\title{
Preeclampsia - will orphan drug status facilitate innovative biological therapies?
}

\author{
Sinuhe Hahn* \\ Laboratory for Prenatal Medicine, Department of Biomedicine, University Hospital Basel, Basel, Switzerland
}

Edited by:

Issam Lebbi, Ob-Gyn and Fertility

Private Clinic, Dream Center, Tunisia

\section{Reviewed by:}

Ralph Kay Heinrich Nanan, The

University of Sydney, Australia

Nándor Gábor Than, Hungarian

Academy of Sciences, Hungary

\section{*Correspondence:}

Sinuhe Hahn, Laboratory for Prenatal Medicine, Department of

Biomedicine, University Hospital

Basel, Hebelstrasse 20, Basel CH

4031, Switzerland

e-mail: sinuhe.hahn@usb.ch
It is generally accepted that the development of novel therapies to treat pregnancy-related disorders, such as preeclampsia, is hampered by the paucity of research funding. Hence, it is with great interest to become aware of at least three novel therapeutic approaches for the treatment of this disorder: exploiting either the anticoagulant activity of antithrombin, the free radical scavenging activity of alpha-1-microglobulin, or the regenerative capacity of placenta-derived mesenchymal stem cells. As these projects are being carried out by small biotech enterprises, the question arises of how they are able to fund such undertakings. A novel strategy adopted by two of these companies is that they successfully petitioned US and EU agencies in order that preeclampsia is accepted in the register of rare or orphan diseases. This provides a number of benefits including market exclusivity, assistance with clinical trials, and dedicated funding schemes. Other strategies to supplement meager research funds, especially to test novel approaches, could be crowdfunding, a venture that relies on intimate interaction with advocacy groups. In other words, preeclampsia meets Facebook. Perhaps similar strategies can be adopted to examine novel therapies targeting either the imbalance in pro- or anti-angiogenic growth factors, complement activation, reduced levels of placenta protein 13 , or excessive neutrophil activation evident in preeclampsia.

Keywords: orphan disease, crowdfunding, advocacy groups, social networking, antithrombin, alpha-1microglobulin, placental mesenchymal stem cells

\section{INTRODUCTION}

Obstetrical concerns such as preterm labor (PTL), intra-uterine fetal growth restriction (IUGR), or preeclampsia (PE) remain huge concerns with regard to maternal or fetal morbidity or mortality (1-3). Indeed, prematurity has recently been listed as the leading cause of child death world-wide, accounting for almost 1 million of the 6.3 million children who die before the age of $5(4,5)$.

Although there has been considerable improvement in Western Europe, Canada, and the US to reduce maternal mortality associated with preeclampsia, it still accounts for one of the leading causes of maternal mortality during pregnancy (3). In developing countries, these rates are significantly higher, especially in cases with severe early onset PE (6) or due to the progression to "fullblown" eclampsia, where mortality rates can be as high as $15 \%$ (3). All in all it is a sad reflection on global health care that almost 800 women die daily as a result of pregnancy-associated complications (7), and it begs the question why efficacious intervention is so slow in forthcoming or implementation (8).

Abbreviations: A1M, alpha-1-microglobulin; COMP, Committee for Orphan Medicinal Products; EMA, European Medicines Agency; FDA, Food and Drug Administration; IND, investigational new drug; IUGR, intra-uterine fetal growth restriction; ODA, Orphan Drug Act; NORD, National Organization for Rare Disorders; PE, preeclampsia; PIFG, placenta growth factor; PLX, mesenchymal-like stem cells from the placenta; PP13, placental protein 13; PTL, preterm labor; rAT, recombinant antithrombin; sFlt-1, soluble fms-like tyrosine kinase-1; VEGF, vascular endothelial growth factor

\section{WHY THE PROGRESS IN THE DEVELOPMENT OF} THERAPEUTICS IN FETO-MATERNAL MEDICINE SO SLOW?

Although the health care burden by pregnancy-related conditions, specifically $\mathrm{PE}$, is considerable with an estimated global health care cost of $\$ 3$ billion, it is dwarfed by the incidence of cancer, which is approximately 28 times greater ( 8.2 million deaths per annum) (9). A further concern that could hinder the active participation of pharmaceutical industries in the development of new drugs for prenatal use is the disaster experienced with thalidomide, due to its unexpected teratogenic effect (10). It is of interest that the underlying mechanism has only recently elucidated in 2014, several decades later (11). A further issue is that the relationship between patient and physician in the Internet age is complicated by the reliance of the former on untrustworthy data or unfounded skepticism of new untried developments $(12,13)$.

Consequently, the argument by pharmaceutical companies, or diverse research funding agencies to focus their resources on more pressing concerns, may at first hand appear rational. However, closer scrutiny indicates that global R\&D funding for pregnancyassociated complications is grossly underfunded, either by the private sector or national bodies, with less than $1 \%$ or the health research budget in the US or UK being allocated to the topic of reproductive health $(14,15)$. This indicates that pressing obstetrical concerns such as PE have been related to the status of "orphan diseases" or less, and consequently is listed as such by the Food and Drag Administration (FDA) and European Commission (16). 
Such scientific relegation has, however, led to an almost complete stifling of the development of new therapeutic agents for use in pregnancy, with the result that physicians are increasingly obliged to resort to "off-label" use of drugs for which no safety indication is available (17-19).

\section{DOES BEING LABELED AN ORPHAN DISEASE HAVE ANY BENEFITS?}

It is unclear why PE could be listed as an "orphan or rare disease" as the defining criteria for such status is an incidence of less than 5 in 10,000 individuals, granted that PE affects between 3 and $8 \%$ of all pregnancies (20). In the context of the entire population, however, the number of people affected by $\mathrm{PE}$ is quite small, and has been estimated to be of the order of 3.8 per 10,000 , thereby comfortably securing a slot in the rare disease catalog (16).

A driving force behind the US Orphan Drug Act (ODA) of 1983 and similar European, Japanese, Australian, or Singaporean regulations was the decision that "patients suffering from rare conditions should be entitled to the same quality of treatment as other patients" (21). The main aim of such legislation is to provide specific incentives to promote drug development for rare conditions. These include market exclusivity, reduction in regulatory fees or subsidies (tax breaks) with clinical trials (21). In addition, special funding schemes have been developed by the NIH (Office of Rare Diseases Research), the EU, and other institutions (NORD: National Organization for Rare Disorders), specifically targeting rare conditions (22). Successful funding, however, may require lobbying or engagement by advocacy groups (23). Consequently, successful funding may in future require considerable political action and mobilization of interest groups.

\section{IS CROWDFUNDING THE SOLUTION?}

If scientific success in future may depend on a meaningful interaction with advocacy groups, it appears obvious that this scenario may be exploited to secure necessary financial resources by means of crowdfunding. A development of social media and globally linked communities, crowdfunding, is a method of raising venture funds from a large number of individuals via the Internet (24-28). To date most crowdfunding approaches have been used in the arts or technology development, but scientific usage is increasing rapidly.

An examination of 159 crowdfunding attempts using the \#Scifund platform indicated that success largely depended on the degree of interaction between scientists and their audience, and the ability to expand this network effectively (24). Although the turn-over generated by the international crowdfunding industry is proposed to be greater than $\$ 1$ billion, with more than $\$ 200$ million being raised via a single website, the rewards for the scientific community have been less spectacular, with the average amount secured estimated to be less than $\$ 50,000(24,26,27)$.

Nevertheless, crowdfunding may play an important role in assisting the establishment of academic spin-off biotech companies geared toward the development of innovative therapies (25). The incentive for crowdfunding participants in this instance is the feature of equity and the possibility of a very high rate of return.

\section{ARE ANY INNOVATIVE BIOLOGICAL THERAPIES BEING DEVELOPED?}

In view of the largely negative preamble in this mini-review, it is gratifying to note that at least three innovative biological therapeutic strategies are being pursued for the treatment of PE. It is also noteworthy that all three are being carried out by small newly established companies, solidifying the suspicion that PE does is not an interesting feature for large pharmaceutical companies.

The first of these small companies is Revo Biologics Inc., which is investigating the use of recombinant antithrombin (rAT), termed ATryn ${ }^{\circledR}$, as an Investigational New Drug (IND) for the treatment of preeclampsia in pregnant women. Their goal is not a full cure but rather to prolong gestation, thereby decreasing fetal or neonatal morbidity or mortality (29).

The rationale behind the approach of Revo Biologics Inc., is that preeclampsia is associated with a pro-thrombotic condition (30), and that previous use of anti-coagulants, such as antithrombin, has been shown to have some benefit $(29,30)$. This includes at least two prospective case-control or feasibility studies conducted in Italy and Japan (31-33).

Enrollment to test ATryn ${ }^{\circledR}$ is underway in a Phase 3 clinical trial termed Preserve-1 (Prospective Randomized Evaluation of the Safety and Efficacy of Recombinant Antithrombin in Very Preterm Preeclampsia) (29).

A second approach is being explored by A1M Pharma AB in Sweden, a biotech spin-off from Lund University, which focuses on the finding by the founders that alpha-1-microglobulin (A1M) can act as a scavenger and remove toxic free radicles (34). By the use of a sheep model for PE, which is induced by starvation-mediated hemolysis, it was shown that exogenous A1M application lead to significant amelioration, detected by an examination of placental and kidney pathology (35). It is unclear if any clinical trials have been launched or are planned to test A1M application in human patients. Of interest is that A1M Pharma successfully lobbied the European Medicines Agency (EMA) Committee for Orphan Medicinal Products (COMP) in order to secure an Orphan Drug status for preeclampsia.

A third very intriguing development is that pursued by the Israeli company Pluristem Therapeutics Inc., which has a series of proprietary technologies focused on the isolation and expansion of mesenchymal-like stem cells from the placenta (PLX) (36). The use of these PLX cells has been explored for the treatment of ischemia or to improve the engraftment of cord blood hemopoietic stem cells (37-39). It now appears that Pluristem is considering the use of these PLX cells for the treatment of preeclampsia, and is following a similar strategy to that of A1M Pharma, in that it has submitted a FDA Orphan Drug application for PE (40).

\section{COULD OTHER STRATEGIES BE EXPLORED FOR THE DEVELOPMENT OF NOVEL BIOLOGICAL THERAPIES?}

The past decade has seen a huge expansion in our knowledge of the underlying etiology involved the development of PE (41). These include the discovery of an imbalance in the pro-angiogenic cytokine PIGF (Placenta Growth Factor) and the anti-angiogenic factor sFlt-1 (soluble fms-like tyrosine kinase 1) in cases at-risk for $\mathrm{PE}$, and the examination of how this anomaly to contributes to endothelial dysfunction (42). Additional discoveries include 
the contribution of complement dysregulation to placental damage (43), the possible involvement of placental galectins such as PP13 (placental protein 13) in placental development and immune modulation (44), or the excessive occurrence of neutrophil extracellular traps (NETs) in preeclamptic placentae (45).

Of these the elevated presence of the anti-angiogenic factors sFlt-1 would seem to be a prime target, as it has previously been shown that extracorporeal removal of this factor by apheresis can extend the pregnancy of women with manifest early onset PE by as much as 23 days (46). An alternative may be to target complement dysregulation, since treatment with a specific inhibitor (eculizumab) has been shown to significantly prolong gestation in a case with PE/HELLP syndrome, thereby improving neonatal outcome (47).

Treatment with recombinant PP13 may be an attractive option in future, granted that its application in pregnant rats is suggested to reduce blood pressure (44). The involvement of excessive NETosis in the etiology of auto-inflammatory conditions such as rheumatoid arthritis $(48,49)$ or systemic lupus erythematosus (SLE) $(50,51)$ opens up the possibility that novel therapeutics will be developed to counter this undesired neutrophil activity (52). This could pave the way for possible use in PE.

\section{WHAT IS THE WAY FORWARD?}

The low level of funding in reproductive medicine is a challenge, which need to be overcome if effective therapies are to be developed for the numerous concerns which continue to beset obstetrical practice. On the one hand this may rely on innovative strategies such as crowdfunding or to somewhat subversive methods, such as applying for orphan disease status. The success of either will depend largely on adequate lobbying, which implies that much closer ties with advocacy groups using social networks will become the order of the day.

\section{CONCLUDING REMARKS}

In this review the focus was on three small companies who are driving the development of new therapeutic strategies for the treatment of PE, which makes it clear that innovation does not rely on huge funding bodies or multinational pharmaceutical companies. Rather, like David when facing Goliath, it relies on flexibility, nimbleness of feet, and a vision or calling to make a significant contribution to the betterment of humankind.

\section{REFERENCES}

1. Brosens I, Pijnenborg R, Vercruysse L, Romero R. The "great obstetrical syndromes" are associated with disorders of deep placentation. Am J Obstet Gynecol (2011) 204:193-201. doi:10.1016/j.ajog.2010.08.009

2. Romero R, Dey SK, Fisher SJ. Preterm labor: one syndrome, many causes. Science (2014) 345:760-5. doi:10.1126/science. 1251816

3. Ghulmiyyah L, Sibai B. Maternal mortality from preeclampsia/eclampsia. Semin Perinatol (2012) 36:56-9. doi:10.1053/j.semperi.2011.09.011

4. Lawn JE, Kinney M. Preterm birth: now the leading cause of child death worldwide. Sci Transl Med (2014) 6:263ed221. doi:10.1126/scitranslmed.aaa2563

5. Liu L, Oza S, Hogan D, Perin J, Rudan I, Lawn JE, et al. Global, regional, and national causes of child mortality in 2000-13, with projections to inform post2015 priorities: an updated systematic analysis. Lancet (2014). doi:10.1016/ S0140-6736(14)61698-6

6. Sibai BM. What to expect from expectant management in severe preeclampsia at $<34$ weeks gestation: pregnancy outcomes in developed vs developing countries. Am J Obstet Gynecol (2013) 209:400-1. doi:10.1016/j.ajog.2013.08.024
7. WHO Fact Sheet No. 348: Maternal Mortality (2014). Available from: http: //www.who.int/mediacentre/factsheets/fs348/en/

8. Fisk NM, Atun R. Market failure and the poverty of new drugs in maternal health. PLoS Med (2008) 5:e22. doi:10.1371/journal.pmed.0050022

9. WHO Fact Sheet No. 297: Cancer (2015). Available from: http://www.who.int/ mediacentre/factsheets/fs297/en/

10. Ridings JE. The thalidomide disaster, lessons from the past. Methods Mol Biol (2013) 947:575-86. doi:10.1007/978-1-62703-131-8_36

11. Fischer ES, Böhm K, Lydeard JR, Yang H, Stadler MB, Cavadini S, et al. Structure of the DDB1-CRBN E3 ubiquitin ligase in complex with thalidomide. Nature (2014) 512:49-53. doi:10.1038/nature13527

12. Palosse-Cantaloube L, Lacroix I, Rousseau V, Bagheri H, Montastruc JL, Damase-Michel C. Analysis of chats on French internet forums about drugs and pregnancy. Pharmacoepidemiol Drug Saf (2014) 23:1330-3. doi:10.1002/ pds.3709

13. Koren G, Madjunkova S, Maltepe C. Bias against the null hypothesis: scaring pregnant women about drugs in pregnancy. Can Fam Physician (2014) 60: 441-2.

14. Fisk NM, Atun R. Systematic analysis of research underfunding in maternal and perinatal health. BJOG (2009) 116:347-56. doi:10.1111/j.1471-0528.2008. 02027.x

15. Gross CP, Anderson GF, Powe NR. The relation between funding by the National Institutes of Health and the burden of disease. N Engl J Med (1999) 340:1881-7. doi:10.1056/NEJM199906173402406

16. Orphanet: Preeclampsia (ORPHA275555) (2014). Available from: http://www. orpha.net/consor/cgi-bin/OC_Exp.php?lng=EN\&Expert=275555

17. Fisk NM, Atun R. Public-private partnership in cord blood banking. BMJ (2008) 336:642-4. doi:10.1136/bmj.39489.454699.AD

18. Fisk NM, McKee M, Atun R. Relative and absolute addressability of global disease burden in maternal and perinatal health by investment in R\&D. Trop Med Int Health (2011) 16:662-8. doi:10.1111/j.1365-3156.2011.02778.x

19. Rayburn WF, Turnbull GL. Off-label drug prescribing on a state university obstetric service. J Reprod Med (1995) 40:186-8.

20. Clarke JT, Coyle D, Evans G, Martin J, Winquist E. Toward a functional definition of a "rare disease" for regulatory authorities and funding agencies. Value Health (2014) 17:757-61. doi:10.1016/j.jval.2014.08.2672

21. Hall AK, Carlson MR. The current status of orphan drug development in Europe and the US. Intractable Rare Dis Res (2014) 3:1-7. doi:10.5582/irdr.3.1

22. Moliner AM. Creating a European Union framework for actions in the field of rare diseases. Adv Exp Med Biol (2010) 686:457-73. doi:10.1007/978-90-4819485-8_25

23. Dunkle M, Pines W, Saltonstall PL. Advocacy groups and their role in rare diseases research. Adv Exp Med Biol (2010) 686:515-25. doi:10.1007/978-90-4819485-8_28

24. Byrnes JE, Ranganathan J, Walker BL, Faulkes Z. To crowdfund research, scientists must build an audience for their work. PLoS One (2014) 9:e110329. doi:10.1371/journal.pone.0110329

25. Brenan J. Science by the masses: is crowdfunding the future for biotech start-ups? IEEE Pulse (2014) 5:59-62. doi:10.1109/MPUL.2013.2289465

26. Dragojlovic N, Lynd LD. Crowdfunding drug development: the state of play in oncology and rare diseases. Drug Discov Today (2014) 19:1775-80. doi:10.1016/ j.drudis.2014.06.019

27. Perlstein EO. Anatomy of the Crowd4Discovery crowdfunding campaign. Springerplus (2013) 2:560. doi:10.1186/2193-1801-2-560

28. Siva N. Crowdfunding for medical research picks up pace. Lancet (2014) 384:1085-6. doi:10.1016/S0140-6736(14)61661-5

29. Paidas MJ, Sibai BM, Triche EW, Frieling J, Lowry S; PRESERVE-1 Study Group. Exploring the role of antithrombin replacement for the treatment of preeclampsia: a prospective randomized evaluation of the safety and efficacy of recombinant antithrombin in very preterm preeclampsia (PRESERVE-1). Am J Reprod Immunol (2013) 69:539-44. doi:10.1111/aji.12091

30. Jacobsen AF, Skjeldestad FE, Sandset PM. Incidence and risk patterns of venous thromboembolism in pregnancy and puerperium - a register-based case-control study. Am J Obstet Gynecol (2008) 198(233):e231-7.

31. Paternoster DM, Fantinato S, Manganelli F, Milani M, Nicolini U, Girolami A. Efficacy of AT in pre-eclampsia: a case-control prospective trial. Thromb Haemost (2004) 91:283-9.

32. Maki M, Kobayashi T, Terao T, Ikenoue T, Satoh K, Nakabayashi M, et al. Antithrombin therapy for severe preeclampsia: results of a double-blind, 
randomized, placebo-controlled trial. BI51.017 Study Group. Thromb Haemost (2000) 84:583-90.

33. Kobayashi T, Terao T, Ikenoue T, Sameshima H, Nakabayashi M, Kajiwara Y, et al. Treatment of severe preeclampsia with antithrombin concentrate: results of a prospective feasibility study. Semin Thromb Hemost (2003) 29:645-52. doi:10.1055/s-2004-815632

34. Akerstrom B, Gram M. A1M, an extravascular tissue cleaning and housekeeping protein. Free Radic Biol Med (2014) 74:274-82. doi:10.1016/j.freeradbiomed. 2014.06.025

35. Wester-Rosenlöf L, Casslén V, Axelsson J, Edström-Hägerwall A, Gram M, Holmqvist M, et al. A1M/alpha1-microglobulin protects from heme-induced placental and renal damage in a pregnant sheep model of preeclampsia. PLoS One (2014) 9:e86353. doi:10.1371/journal.pone.0086353

36. Prather W. Pluristem Therapeutics, Inc. Regen Med (2008) 3:117-22. doi:10. 2217/17460751.3.1.117

37. Prather WR, Toren A, Meiron M. Placental-derived and expanded mesenchymal stromal cells (PLX-I) to enhance the engraftment of hematopoietic stem cells derived from umbilical cord blood. Expert Opin Biol Ther (2008) 8:1241-50. doi:10.1517/14712598.8.8.1241

38. Prather WR, Toren A, Meiron M, Ofir R, Tschope C, Horwitz EM. The role of placental-derived adherent stromal cell (PLX-PAD) in the treatment of critical limb ischemia. Cytotherapy (2009) 11:427-34. doi:10.1080/14653240902849762

39. Lahiani A, Zahavi E, Netzer N, Ofir R, Pinzur L, Raveh S, et al. Human placental expanded (PLX) mesenchymal-like adherent stromal cells confer neuroprotection to nerve growth factor (NGF)-differentiated PC12 cells exposed to ischemia by secretion of IL-6 and VEGF. Biochim Biophys Acta (2015) 1853:422-30. doi:10.1016/j.bbamcr.2014.11.009

40. Pluristem Therapeutics Submits FDA Orphan Drug Application for Preeclampsia. RTT News (2014). Available from: http://www.rttnews.com/2272745/pluristemtherapeutics-submits-fda-orphan-drug-application-for-preeclampsia.aspx

41. Chaiworapongsa T, Chaemsaithong P, Yeo L, Romero R. Pre-eclampsia part 1: current understanding of its pathophysiology. Nat Rev Nephrol (2014) 10:466-80. doi:10.1038/nrneph.2014.102

42. Naljayan MV, Karumanchi SA. New developments in the pathogenesis of preeclampsia. Adv Chronic Kidney Dis (2013) 20:265-70. doi:10.1053/j.ackd. 2013.02.003

43. Lynch AM, Salmon JE. Dysregulated complement activation as a common pathway of injury in preeclampsia and other pregnancy complications. Placenta (2010) 31:561-7. doi:10.1016/j.placenta.2010.03.010

44. Than NG, Balogh A, Romero R, Kárpáti E, Erez O, Szilágyi A, et al. Placental protein 13 (PP13) - a placental immunoregulatory galectin protecting pregnancy. Front Immunol (2014) 5:348. doi:10.3389/fimmu.2014.00348

45. Hahn S, Giaglis S, Hoesli I, Hasler P. Neutrophil NETs in reproduction: from infertility to preeclampsia and the possibility of fetal loss. Front Immunol (2012) 3:362. doi:10.3389/fimmu.2012.00362
46. Thadhani R, Kisner T, Hagmann H, Bossung V, Noack S, Schaarschmidt $\mathrm{W}$, et al. Pilot study of extracorporeal removal of soluble fms-like tyrosine kinase 1 in preeclampsia. Circulation (2011) 124:940-50. doi:10.1161/ CIRCULATIONAHA.111.034793

47. Burwick RM, Feinberg BB. Eculizumab for the treatment of preeclampsia/HELLP syndrome. Placenta (2013) 34:201-3. doi:10.1016/j.placenta.2012. 11.014

48. Khandpur R, Carmona-Rivera C, Vivekanandan-Giri A, Gizinski A, Yalavarthi S, Knight JS, et al. NETs are a source of citrullinated autoantigens and stimulate inflammatory responses in rheumatoid arthritis. Sci Transl Med (2013) 5:178ra140. doi:10.1126/scitranslmed.3005580

49. Sur Chowdhury C, Giaglis S, Walker UA, Buser A, Hahn S, Hasler P. Enhanced neutrophil extracellular trap generation in rheumatoid arthritis: analysis of underlying signal transduction pathways and potential diagnostic utility. Arthritis Res Ther (2014) 16(3):R122. doi:10.1186/ar4579

50. Garcia-Romo GS, Caielli S, Vega B, Connolly J, Allantaz F, Xu Z, et al. Netting neutrophils are major inducers of type I IFN production in pediatric systemic lupus erythematosus. Sci Transl Med (2011) 3:73ra20. doi:10.1126/scitranslmed. 3001201

51. Lande R, Ganguly D, Facchinetti V, Frasca L, Conrad C, Gregorio J, et al. Neutrophils activate plasmacytoid dendritic cells by releasing self-DNA-peptide complexes in systemic lupus erythematosus. Sci Transl Med (2011) 3:73ra19. doi:10.1126/scitranslmed.3001180

52. Gupta A, Giaglis S, Hasler P, Hahn S. Efficient neutrophil extracellular trap induction requires mobilization of both intracellular and extracellular calcium pools and is modulated by cyclosporine A. Plos One (2014) 9(5):e97088. doi:10.1371/journal.pone.0097088

Conflict of Interest Statement: The author declares that the research was conducted in the absence of any commercial or financial relationships that could be construed as a potential conflict of interest.

Received: 19 January 2015; accepted: 12 February 2015; published online: 26 February 2015.

Citation: Hahn S (2015) Preeclampsia - will orphan drug status facilitate innovative biological therapies? Front. Surg. 2:7. doi: 10.3389/fsurg.2015.00007

This article was submitted to Obstetrics and Gynecology, a section of the journal Frontiers in Surgery.

Copyright $\odot 2015$ Hahn. This is an open-access article distributed under the terms of the Creative Commons Attribution License (CC BY). The use, distribution or reproduction in other forums is permitted, provided the original author(s) or licensor are credited and that the original publication in this journal is cited, in accordance with accepted academic practice. No use, distribution or reproduction is permitted which does not comply with these terms. 